\title{
Susceptibility of Different Species of Ticks (Acari: Ixodidae) to an Entomopathogenic Fungus in Tanzania
}

\author{
Never Zekeya ${ }^{1,2, *}$, Ernest R Mbega², and Humphrey Ndossi ${ }^{1}$ \\ ${ }^{1}$ Tanzania Industrial Research and Development Organization (TIRDO), Dar es salaam, Tanzania \\ ${ }^{2}$ Department of Sustainable Agriculture and Biodiversity Ecosystem Management, School of Life Science and Bioengineering, The Nelson Mandela \\ African Institution of Science and Technology, Arusha, Tanzania
}

\begin{abstract}
*Corresponding author: Never Zekeya, Department of Sustainable Agriculture and Biodiversity Ecosystem Management, School of Life Science and Bioengineering, The Nelson Mandela African Institution of Science and Technology, Arusha, Tanzania, E-mail: nmwambela@ yahoo.com
\end{abstract}

Received: 08 May, 2020 | Accepted: 27 May, 2020 | Published: 06 Jun, 2020

Citation: Zekeya N, Mbega ER, Ndossi H (2020) Susceptibility of Different Species of Ticks (Acari: Ixodidae) to an Entomopathogenic Fungus in Tanzania. J Anim Sci Res 4(2): dx.doi.org/10.16966/2576-6457.139

Copyright: (C) 2020 Zekeya N, et al. This is an open-access article distributed under the terms of the Creative Commons Attribution License, which permits unrestricted use, distribution, and reproduction in any medium, provided the original author and source are credited.

\section{Abstract}

Ticks and tick-borne disease cause severe skin damage on livestock as well as wildlife mortifying animal health and byproduct for processing and tourism industries. Management of ticks by conventional acaricidal is environmentally and economically unaffordable in Tanzania. This study evaluated the effectiveness of a novel entomopathogenic fungi Aspergillus oryzae (TZ/P/2018/000035) against three species of ticks (Acari: loxididae); Rhipicephalus appendiculatus, Hyalomma anatolicum and Amblyomma gemma by spraying $0.2 \mathrm{~mL} /$ tick of $1 \times 10^{6}, 1 \times 10^{7}, 1 \times 10^{8}$ conidia/ $\mathrm{mL}$ of $A$. oryzae and control (water and $0.5 \%$ triton $\mathrm{x}-100$ ) in $35.5^{\circ} \mathrm{C}$ and $85 \% \mathrm{RH}$ repeated at $20.5^{\circ} \mathrm{C}$ and $70 \% \mathrm{RH}$ in the laboratory conditions at Nelson Mandela African Institution of Science and Technology, Arusha. Results showed that at $1 \times 10^{8}$ conidial $/ \mathrm{mL}, A$. oryzae caused high mortality rate averaging $88.2 \%, 72.5 \%$ and $67.9 \%$ within $6.25 \pm 0.75$ days, $7.55 \pm 0.59$ days and $11.9 \pm 0.65$ days in $H$. anatolicum R. appendiculatus and $A$. gemma respectively, whereas in control the highest mortality rate reached $12.5 \%, 11.0 \%$ and $6.5 \%$ after $22.50 \pm 1.2,24.6 \pm 0.9$ and $28 \pm 2.9$ days in $R$. appendiculatus, $H$. anatolicum and $A$. gemma respectively at $20.5^{\circ} \mathrm{C}$ and $70 \% \mathrm{RH}$. It was also revealed that at $1 \times 10^{8} \mathrm{conidial} / \mathrm{mL}$ of $A$. oryzae reduced oviposition rate in $A$. gemma whereby $94.8 \pm 10.74$ eggs/female were laid compared to control that laid $354.15 \pm 42.65 \mathrm{egg} / \mathrm{female}$. Again, eggs averaging $166.20 \pm 7.5$ eggs/female were laid in $H$. anatolicum treated with $A$. oryzae at $1.0 \times 10^{8}$ conidia/mL compared to control that laid eggs averaging $416.25 \pm 21.71 /$ female in cold. This study revealed that $A$. oryzae was effective for control of ticks could be applied in agricultural fields to protect animal from tick's damage consequently improving animal products in processing industry in Tanzania.

Keywords: Animal Health; Aspergillus oryzae; Entomopathogenic fungi; Hides and skin damage; Tick diseases; Tanzania

\section{Introduction}

The occurrence and diversity of ticks' species and associated predicaments affect animal husbandry, wildlife and allied industry in Africa [1-3]. Hard ticks are reported as key parasites of cattle, goat and sheep causing high economic loss in Africa including Tanzania [4-6]. The most common and serious ticks of East Africa are Amblyomma gemma, Rhipicephalus appendiculatus and Hyalomma anatolicum affecting both domesticated and wild animals $[7,8]$. They affect animal health by direct parasitism and transmission of Tick Borne Diseases (TBDs) leading to low quality of animal products including milk, meat poor hides and skins due to lesion hindering utilization of animal products in industries [7,9-12]. The impact of hard ticks on skins is noticeably as they puncture direct through sucking blood leaving the skin wounded making hides unsuitable for tannery industry in Africa [12-14]. The deprived and reject hides and skins by tanning industry lower manufacturing capability and exportation of leather products affecting economy of the country [15-17]. Impacts of ticks do not end on large mammals but also small ruminant and birds including ostrich leading to severe skin damage and loss $[13,18$ 21]. However, poor animal keeping and grazing method such as free range landraces especially in pastoralist communities have been reported to amplify the problem in Africa including Tanzania [2224]. The hard ticks especially the A. gemma and R. appendiculatus are the main cause of skins and hides damage in Africa $[25,26]$ whereas H. marginatum infest bird skin as well. The overall effect of tick on animals and birds lead to downgrading of hides and skins and finally rejection by processing industries [16,15]. In Somalia and Ethiopia for instance, Ticks and Tick-Borne Diseases (TTBDs) have been reported to have high impact on tannery industry leading to sluggish in leather industry [27-29].

Management of ticks has been solely based on chemicals through spray and dipping of animals in chemical such as organophosphate 
and organochlorine where resistance has been reported as well as negative impact to animals and environment [30-32]. Several studies have conducted is searching for new acaricidal compound for effective control of tick [33]. However, use of alternative methods such as botanicals and biocontrols has been reported to improve the quality of animal skin [18,31]. A study by Kalala W, et al. [34] reported the potential of Commiphora swynnertoni on control of tick in Tanzania. Other studies reported the effect of entomopathognic fungi such as Beauvaria bassiana, Metarhizium anisopliae, Lecanicillium salliotae and Lecanicillium lecanii against ticks [35-40] whereas A. oryzae has been reported to be effective against Camel tick eggs [41]. However, none of the study reported the acaricidal activity of Aspergillus oryzae on three deadly species of ticks namely; Amblyomma gemma Rhipicephalus appendiculatus and Hyalomma anatolicum (Korch, 1844) in Tanzania. It is in this vein that new isolates of A. oryzae was screened for is efficacy against three species of ticks in Tanzania.

\section{Material and Methods}

\section{Collection of ticks and identification}

Ticks were collected at Oldoinyo was village in Arusha region and identification by the Tropical Pesticides Research Institute (TPRI) in which three species namely as Amblyomma gemma, the biggest female tick, Rhipicephalus appendiculatus and Hyalomma marginatum were identified. Fungal isolate; Aspergillus oryzae (TZ/P/2018/000035) previously isolated for management of Tuta absoluta was offered by Plant Biodefender Limited, Moshi-Tanzania

\section{Preparation of $A$. oryzae concentration}

Working concentration were prepared and selected based on [42] methods. Fungal isolate was sub-cultured on Potato Dextrose Agar (PDA) in Petri dishes to confirm its viability. After 5 days of full maturation, spores were gently scrapped from the media by suspending into $10 \mathrm{~mL}$ sterile distilled water with $0.1 \%$ Triton X-100 per Petri dish to make a stock suspension. After mixing suspension in a flask, the concentration of stock solution was accessed by a haemocetometer neubauer (Manfield, German) that was $1.1 \times 10^{9} \mathrm{conidial} / \mathrm{mL}$ which was further diluted to get working concentrations of $1.0 \times 10^{6}$ conidia/ $\mathrm{mL}, 1.0 \times 10^{7}$ conidia/mL and $1.0 \times 10^{8}$ conidia/mL by the addition of sterile distilled water.

\section{Acaricidal activity of $A$. oryzae on adult ticks}

Twenty ticks, ten (10) engorged female and (10) male adults' ticks with an average weight of $(2.62 \pm 0.60 \mathrm{~g})$ A. gemma, $(1.5 \pm 0.27 \mathrm{~g})$ $R$. appendiculatus and $(0.9 \pm 0.25 \mathrm{~g}) \mathrm{H}$. anatolicum were sprayed by $0.5 \mathrm{ml}$ containing $1 \times 10^{7}$ and $1 \times 10^{8} \mathrm{conidial} / \mathrm{mL}$ of $A$. oryzae and control (containing water and $0.5 \%$ triton $\mathrm{X}-100)$. Treated ticks were placed in plastic lunch box $(21 \mathrm{~cm} \times 12 \mathrm{~cm} \times 7 \mathrm{~cm})$ lined with moist paper towel. All treated ticks were fed once a day by fresh blood by using plastic syringe. Tick mortality was recorded after every 48 hours whereas dead ticks were removed and incubated on moist petri dish for observation of fungal growth. The experiment was replicated four times. For the female ticks' bioassay, mortality was recorded post treatment to observe effect of treatment on oviposition until death.

\section{Effect of A. oryzae on oviposition}

Ovicidal effect of biopesticides was conducted according to [41] method with minor modification whereby fully engorged female ticks were exposed to at $1 \times 10^{6}, 1 \times 10^{7} \mathrm{conidial} / \mathrm{mL}, 1 \times 10^{8} \mathrm{conidial} / \mathrm{mL}$ and control by spraying $0.5 \mathrm{ml}$ of suspension on ticks. Oviposition inhibition rate was determined by counting number of eggs laid per day dividing by number of treated engorged female ticks to obtain average eggs laid. Weight of ticks before and after laying eggs was recorded to establish relationship between weight and oviposition rate.

\section{Data and statistics analysis}

Data on efficacy biopesticides against three species of ticks were presented as adult mortality rate, adult survival duration and oviposition rate that were analysed with the Proc GLM procedure of SAS, version 9.1 (SAS Institute, Cary, NC, USA) and tested for normality and homogeneity of variance. Mortality rate was transformed to $\log$-10 for obtaining normally distributed data sets with equal variance. Adult survival duration and oviposition rate were subjected to analysis of variance (ANOVA) whereas adult mortality rate was subjected to Kruskal Wallis. Bonferroni was used to separate mean difference of adult mortality rate whereas Tukey's Honest Significant difference (HSD) was used to separate mean differences of Adult survival duration and oviposition rate at $5 \%$ level of significance.

\section{Results}

\section{Time effect of $A$. oryzae on species of ticks}

Effect of treatment on survival days of ticks varied significantly $(\mathrm{p}=<0.0001)$ between species of ticks at cold $\left(20.5^{\circ} \mathrm{C}\right.$ and $\left.70 \% \mathrm{RH}\right)$ and warm $\left(35.5^{\circ} \mathrm{C}\right.$ and $\left.85 \% \mathrm{RH}\right)$ conditions, with high activity in all concentrations of $A$. oryzae compared to control. A. oryzae treated ticks had lower survival duration in which survival time was reduced up to $6.25 \pm 0.75$ days in $H$. anatolicum than in A. gemma that survived for $11.9 \pm 0.65$ days whereas $H$. anatolicum and A. gemma in control survived for $31.95 \pm 2.17$ days and $41.35 \pm 1.66$ respectively (Table 1 ). However, the effect of treatment on species of ticks was insignificant $(\mathrm{p}=0.30)$ although A. gemma survived longer compared to $R$. appendiculatus and $H$. anatolicum in both cold and warm conditions (Table 1).

\section{Effect of $A$. oryzae on oviposition rate of engorged female ticks}

The effect of treatment on mortality of engorged female ticks was evaluated by species due to variation in species fecundity. The effect of treatment on oviposition rate of engorged female $R$. appendiculatus varied significantly $(\mathrm{p}=<0.0001)$ in both warm and cold in which at warm temperature high oviposition rate was observed.

A. gemma treated with $A$. oryzae at $1.0 \times 10^{8}$ conidial $/ \mathrm{ml} \mathrm{laid} \mathrm{few}$ eggs in cold temperature in $94.8 \pm 10.74$ compared to control that laid up to $354.15 \pm 42.65 \mathrm{egg} /$ female whereas an average of 166.20 \pm 7.5 eggs/female were laid by $H$. anatolicum treated with $A$. oryzae at $1.0 \times 10^{8} \mathrm{conidial} / \mathrm{ml}$ compared to control that laid eggs averaging $416.25 \pm 21.71 /$ female in cold condition (Table 2 ). In H. anatolicum the oviposition rate was significantly $(\mathrm{p}=<0.0001)$ different between treatments in warm and cold condition respectively, whereas A. oryzae at all concentration treated ticks laid few eggs than control (Table 2).

\section{Effect of A. oryzae on mortality of female engorged ticks}

The effect of treatment on mortality of engorged female ticks was evaluated by species due to variation in species morbidity. The effect of treatment on mortality of engorged female was significantly ( $\mathrm{p}=<0.0001$ ) warm and cold condition respectively, in which $A$. oryzae at $1.0 \times 10^{8}$ conidia/ml caused mortality within few days compared to lower doses $1.0 \times 1^{6}$ conidia $/ \mathrm{ml}$ and $1.0 \times 10^{7}$ conidia $/ \mathrm{ml}$ and control (Table 3). The effect of treatment on mortality of $H$. anatolicum varied significantly in both warm and cold condition $(\mathrm{p}=<0.0001)$, respectively (Table 3). There was also a significant $(\mathrm{p}=<0.0001)$ effect of treatment on survival of engorged female in warm and cold condition whereas $A$. oryzae at $1.0 \times 10^{8}$ conidia $/ \mathrm{ml}$ induced up to $88.2 \%, 72.5 \%$ and $67.9 \%$ 
in R. appendiculatus, H. anatolicum and A. gemma respectively within 3 to 6 days compared to control where $12.5 \%$ mortality was reached in warm condition (Table 3 ).

\section{Virulence of $A$. oryzae on ticks}

From dead ticks treated with $A$. oryzae was observed and reisolated by placing dead ticks on moist petri dishes incubated at $30^{\circ} \mathrm{C}$. After 3 to 10 days, mycelia developed on ticks cuticle treated with A.oryzae and sporulated covering the dead tick indicating the pathogenic activity on ticks. However, none fungal spore was observed to germinate from dead ticks in control plates (Figure 1).

\section{Discussion}

Animals are good source of food, income through tourism whereas byproducts especially hides and skins are essential raw materials in leather processing industry $[43,44]$. Ticks injuries and flushes on animal hides and skins lead to massive economic losses and rejection of raw material in tannery industry [16]. In Tanzania, hard tick A. gemma is common in cattle and wild animals causing high rate of ricketisia whereas $R$. appendiculatus occur in several hosts infesting appendages and ears $[45,46]$. Although use of chemical acaricide is prominent in Tanzania, it is economically and environmentally expensive [5]. This study revealed the potential of new

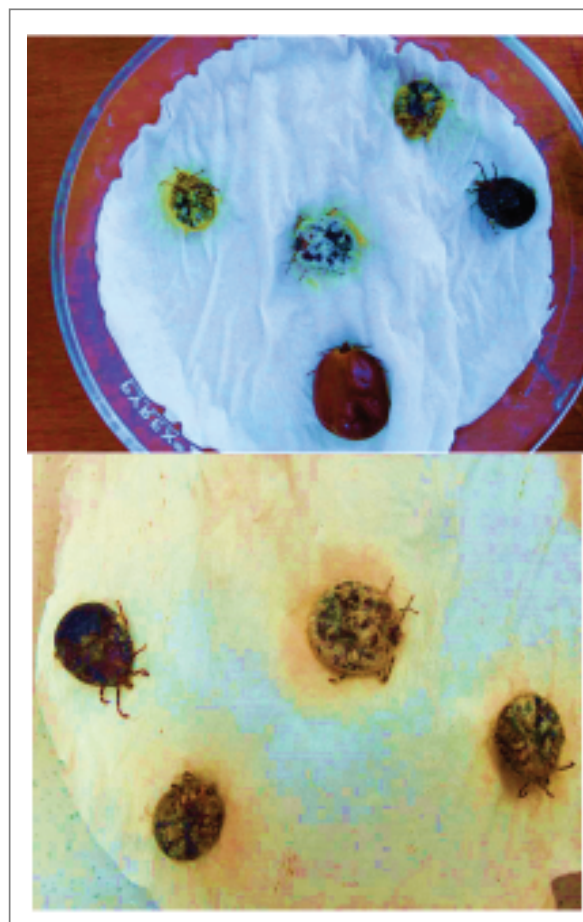

A

Figure 1: Comparison between A. Oryzae treated ticks (A and B) and Control (C) whereby fungal spore propagation on cuticles of $A$. gemma (A), $R$. appendiculatus and $H$. anatolicum (B) whereas no fungal sporulation on A. gemma, R. appendiculatus and H. anatolicum in control (C) after (C) 10 days post mortality.

Table 1: Effect of A. oryzae on survival duration of three species of ticks after exposure to treatment conditions. Different letters show the significant difference where as similar letters show no difference between treatments at $p<0.005$.

\begin{tabular}{|l|c|c|c|c|c|}
\hline \multicolumn{3}{|c|}{ Experimental conditions } & \multicolumn{2}{c|}{ Tick species } \\
\hline \multirow{2}{*}{ Treatment } & Temperature and RH (\%) & $\begin{array}{c}\text { Concentration } \\
\text { (conidia/mL) }\end{array}$ & Amblyomma gemma & Hyalomma anatolicum & Rhipicephalus appendiculutus \\
\hline \multirow{3}{*}{ Control } & $20.5^{\circ} \mathrm{C}+70$ & 0.0 & $41.35 \pm 1.6 \mathrm{a}$ & $31.95 \pm 2.17 \mathrm{a}$ & $27.75 \pm 1.4 \mathrm{a}$ \\
\cline { 2 - 6 } & $35.5^{\circ} \mathrm{C}+85$ & 0.0 & $28 \pm 2.9 \mathrm{ab}$ & $24.6 \pm 0.9 \mathrm{ab}$ & $22.50 \pm 1.2 \mathrm{a}$ \\
\hline \multirow{3}{*}{ A. oryzae } & $20.5^{\circ} \mathrm{C}+70$ & $1.0 \times 10^{6}$ & $16 \pm 0.8 \mathrm{~b}$ & $11.0 \pm 0.5 \mathrm{~b}$ & $13.07 \pm 0.5 \mathrm{~b}$ \\
\cline { 2 - 6 } & $35.5^{\circ} \mathrm{C}+85$ & $1.0 \times 10^{6}$ & $12.9 \pm 1.4 \mathrm{bc}$ & $9.5 \pm 0.3 \mathrm{~b}$ & $12.6 \pm 0.3 \mathrm{~b}$ \\
\hline \multirow{3}{*}{ A. oryzae } & $20.5^{\circ} \mathrm{C}+70$ & $1.0 \times 10^{7}$ & $12.3 \pm 1.5 \mathrm{c}$ & $9.05 \pm 0.4 \mathrm{~b}$ & $12.0 \pm 0.3 \mathrm{~b}$ \\
\cline { 2 - 6 } & $35.5^{\circ} \mathrm{C}+85$ & $1.0 \times 10^{7}$ & $12.6 \pm 0.5 \mathrm{c}$ & $8.3 \pm 0.6 \mathrm{~b}$ & $11.6 \pm 0.4 \mathrm{~b}$ \\
\hline \multirow{2}{*}{ A. oryzae } & $20.5^{\circ} \mathrm{C}+70$ & $1.0 \times 10^{8}$ & $11.1 \pm 0.9 \mathrm{c}$ & $7.9 \pm 0.3 \mathrm{~b}$ & $7.7 \pm 0.4 \mathrm{c}$ \\
\hline P-value & $35.5^{\circ} \mathrm{C}+85$ & $1.0 \times 10^{8}$ & $11.9 \pm 0.6 \mathrm{c}$ & $7.5 \pm 0.5 \mathrm{~b}$ & $6.25 \pm 0.75 \mathrm{c}$ \\
\hline
\end{tabular}


Table 2: Effect of $A$. oryzae on oviposition rate of three species of ticks after exposure to treatment conditions. Different letters show the significant difference where as similar letters show no difference between treatments at $p<0.005$

\begin{tabular}{|l|c|c|c|c|}
\hline \multicolumn{2}{|c|}{ Experimental conditions } & & \multicolumn{2}{c|}{ Tick species } \\
\hline Treatment & Temperature and RH (\%) & Concentration (conidia/mL) & Amblyomma gemma & Hyalomma anatolicuma \\
\hline \multirow{2}{*}{ Control } & $20.5^{\circ} \mathrm{C}+70$ & 0.0 & $354.15 \pm 42.6 \mathrm{a}$ & $416.25 \pm 21.71 \mathrm{a}$ \\
\cline { 2 - 5 } & $35.5^{\circ} \mathrm{C}+85$ & 0.0 & $377.5 \pm 33.7 \mathrm{a}$ & $428.55 \pm 11.90 \mathrm{a}$ \\
\hline \multirow{2}{*}{ A. oryzae } & $20.5^{\circ} \mathrm{C}+70$ & $1.0 \times 10^{6}$ & $306.9 \pm 1.40 \mathrm{~b}$ & $367.25 \pm 11.50 \mathrm{~b}$ \\
\hline A. oryzae & $35.5^{\circ} \mathrm{C}+85$ & $1.0 \times 10^{6}$ & $375 \pm 13.75 \mathrm{~b}$ & $359.50 \pm 9.39 \mathrm{~b}$ \\
\hline \multirow{2}{*}{ A. oryzae } & $20.5^{\circ} \mathrm{C}+70$ & $1.0 \times 10^{7}$ & $218.2 \pm 1.51 \mathrm{bc}$ & $322.25 \pm 8.00 \mathrm{bc}$ \\
\hline P-value & $35.5^{\circ} \mathrm{C}+85$ & $1.0 \times 10^{7}$ & $276.6 \pm 19.7 \mathrm{bc}$ & $212.31 \pm 7.28 \mathrm{bc}$ \\
\hline
\end{tabular}

Table 3: Effect of $A$. oryzae mortality rate of three species of ticks after exposure to different treatment conditions. Different letters show the significant difference where as similar letters show no difference between treatments at $p<0.005$.

\begin{tabular}{|c|c|c|c|c|c|}
\hline \multicolumn{3}{|c|}{ Experimental conditions } & \multicolumn{3}{|c|}{ Tick species } \\
\hline Treatment & Temperature and RH (\%) & Concentration (conidia/MI) & Amblyomma gemma & Hyalomma anatolicum & $\begin{array}{l}\text { Rhipicephalus } \\
\text { appendiculutus }\end{array}$ \\
\hline \multirow{2}{*}{ Control } & $20.5^{\circ} \mathrm{C}+70$ & 0.0 & $4.5 \% a$ & $10.5 \% a$ & $8.2 \% a$ \\
\hline & $35.5^{\circ} \mathrm{C}+85$ & 0.0 & $6.0 \% a$ & $11.0 \% a$ & $12.5 \% a$ \\
\hline \multirow{2}{*}{ A. oryzae } & $20.5^{\circ} \mathrm{C}+70$ & $1.0 \times 10^{6}$ & $36.2 \% b$ & $41.0 \% \mathrm{~b}$ & $40.7 \% \mathrm{~b}$ \\
\hline & $35.5^{\circ} \mathrm{C}+85$ & $1.0 \times 10^{6}$ & $39.9 \% b$ & $51.5 \% \mathrm{~b}$ & $53.2 \% b$ \\
\hline \multirow[t]{2}{*}{ A. oryzae } & $20.5^{\circ} \mathrm{C}+70$ & $1.0 \times 10^{7}$ & $48.5 \% \mathrm{bc}$ & $57.0 \% \mathrm{bc}$ & $58.5 \% \mathrm{bc}$ \\
\hline & $35.5^{\circ} \mathrm{C}+85$ & $1.0 \times 10^{7}$ & $53.6 \% \mathrm{bc}$ & $57.3 \% \mathrm{bc}$ & $64.6 \% \mathrm{bc}$ \\
\hline \multirow{2}{*}{ A. oryzae } & $20.5^{\circ} \mathrm{C}+70$ & $1.0 \times 10^{8}$ & $57.4 \% c$ & $62.5 \% c$ & $68.7 \% \mathrm{c}$ \\
\hline & $35.5^{\circ} \mathrm{C}+85$ & $1.0 \times 10^{8}$ & $67.9 \%$ bc & $72.5 \% \mathrm{~b}$ & $88.2 \%$ bc \\
\hline
\end{tabular}

isolate of $A$. oryzae for control of ticks. This study revealed that $H$. anatolicum and $R$. appendiculatus were more susceptible to fungal $A$. oryzae compared to A. gemma that laid higher number of eggs and survived longer. However, at high concentration of $1.0 \times 10^{8}$ conidial/ $\mathrm{mL}$ both warm and cold conditions $A$. oryzae had high activity on three species of ticks whereas $R$. appendiculatus was more susceptible to than $H$. anatolicum and A. gemma [47]. Less susceptible of $A$. gemma at all treatment conditions could be due to high food reservoir keeping it firmer and more active for long time than other ticks and resist to acaricidal in most East African countries [26].

Other studies have also revealed the potential of entomopathogenic fungi for control of several species of ticks [38,48]. Acaricidal activity of entomopathogenic fungi including Scopulariopsis brevicaulis on Hyalomma anatolicum and Amblyomma spp has also been reported [48-50]. This study revealed that $A$. oryzae was more virulent compared to control on ticks although the infectivity increased with rise in concentration in all species of ticks. The mode of action was through cuticle fungal penetration and infection as Aspegillus species like other fungal spp developed a symbiotic relationship with host ticks and caused pathogenic effect [51].

Other studies reported the activity of M. anisolpliae and B. bassiana against the deadly $H$. anatolicum in laboratory [52]. However, more studies show that a combination of entomopathogenic fungi with other compounds increases virulence toward insect in which $B$. bassiana and acaricidal showed enhanced acaricidal activity [53]. In current study, the oviposition rate was very low in ticks treated with $A$. oryzae compared to control in which high number of eggs were laid this could be due to infertility effect caused by entomopathogenic fungi [51]. Despite of A. gemma having the highest weight than R. appendiculatus and $H$. anatolicum, high number of eggs were laid by Hyalomma species due to high fecundity rate at warm laboratory condition in which other studies revealed similar situation. Low oviposition rate was observed in fungal treated ticks in contrast to control which could be due to virulence effect of $A$. oryzae that caused death prior to oviposition [53]. Even though A. gemma possessed heavy weight than $H$. anatolicum and A. appendiculatus, its fecundity rate declined after treatment with $A$. oryzae showing that fungal pathogenesis extended and inhibited egg oviposition and finally ticks died with their heavy weights. A. oryzae exhibited mortality at all concentration against all species of ticks, however death on A. gemma was delayed compared to $H$. anatolicum and R. appendiculatus which could be due to have hard exoskeleton that absorb slowly spores. In most treatment appendages of ticks showed highest and early virulence than other parts indicating that A. oryzae attack first insect appendages (cuticles) to slow down movement and thereafter causes death. Despite the mortality in 
control after long time of exposure to treatment, no fungal mycelia were reisolated from incubated dead ticks showing the death occurred natural unlike in fungal treated ticks. This substantiate that, fungal biopesticides are the best are natural control of ectoparasite pest as could have dual application in agricultural farms or grazing lands as both plant and animal pest control if sprayed in pastoral areas [35].

\section{Conclusion}

A. oryzae was effective in controlling three species of ticks that threaten animal husbandry and leather industry in Tanzania. Hence this study recommends further field experiment on application of $A$. oryzae as direct spray on animals or soil in grazing environment could be potential for management of ticks and mosquitoes to control skin damage for health animals and protect from Vector Bone Diseases (VTBDs) for improving quality of hides and skins for tanning industry in Tanzania.

\section{Declaration}

Authors declare that no competing interest exist.

\section{Funding}

This work was supported by Deutscher Akademischer Austauschdienst (DAAD) grant number: 57221138 .

\section{Acknowledgement}

Authors acknowledge DAAD/RUFORUM in region /in country scholarship for funding this study. The Tropical Pesticide Research Institute (TPRI) is also acknowledged for assistance in tick identification, Mr Meshack Mollel and other cattle keepers in the area where visited are all acknowledged for their assistance during ticks, hides and skins collection in Longido, Monduli and Arusha districts.

\section{References}

1. Selmi R, Ben Said M, Ben Yahia H, Abdelaali H, Messadi L (2020) Molecular Epidemiology and Phylogeny of Spotted Fever Group Rickettsia in Camels (Camelus Dromedarius) and Their Infesting Ticks From Tunisia. Transbound Emerg Dis 67: 733-744.

2. Kebede N, Fetene $T$ (2012) Population dynamics of cattle ectoparasites in Western Amhara National Regional State, Ethiopia. J Vet Med Anim Health 4: 22-26.

3. Mohammed K, Admasu P (2015) Prevalence of Ixodid Ticks in Small Ruminants in Selected Districts of Fafen Zone, Eastern Ethiopia. Europ J Appl Sci 7: 50-55.

4. Mukolwe SA (2018) Diversity of ticks and tick-borne protozoan parasites from livestock and wildebeests at the Maasai-mara wildlifelivestock interface, Narok county, Kenya. Doctoral dissertation, University of Nairobi, Kenya.

5. Wandiga SO (2001) Use and distribution of organochlorine pesticides. The future in Africa. Pure Appl Chem 73: 1147-1156.

6. Aktas M, Dumanli N, Angin M (2004) Cattle infestation by Hyalomma ticks and prevalence of Theileria in Hyalomma species in the east of Turkey. Vet Parasitol 119: 1-8.

7. Muhanguzi D, Byaruhanga J, Amanyire $W$, Ndekezi $C$, Ochwo S, et al. (2020) Invasive cattle ticks in East Africa: morphological and molecular confirmation of the presence of Rhipicephalus microplus in south-eastern Uganda. Parasite Vector 13: 1-9.

8. Villinger J, Jeneby M, Ong'amo G, Otiende MY, Makhulu EE, et al. (2020) Pathogens, endosymbionts, and blood-meal sources of hostseeking ticks in the fast-changing Maasai Mara wildlife ecosystem. bioRxiv.
9. Yacob H, Ataklty $\mathrm{H}$, Kumsa B (2008) Major ectoparasites of cattle in and around Mekelle, Northern Ethiopia. Entomol Res 38: 126-130.

10. Yacob H, Yalew T, Dinka A (2008b) Ectoparasite prevalences in sheep and in goats in and around Wolaita soddo, Southern Ethiopia. Revue de Médecine Vétérinaire 159: 8-9.

11. Ferede B, Kumsa B, Bsrat A, Kalayou S (2010) Ticks of donkeys in central Oromia regional state, Ethiopia. Revue Méd Vét 161: 121126.

12. Abdela N (2016) Important Cattle Ticks and Tick Born Haemoparasitic Disease in Ethiopia: A Review. Acta Parasitol Glob 7: 12-20.

13. Kebede MC (2013) Effect of Small Ruminant Ectoparasites in the Tanning Industry in Ethiopia: A Review. J Anim Sci Adv 3: 424-430.

14. Beyecha K, Kumsa B, Beyene D (2014) Ectoparasites of goats in three agroecologies in central Oromia, Ethiopia. Comp Clin Path 23: 21-28.

15. Abebayehu T, Kibrom M (2010) Study on Ectoparasitic Defects of Processed Skins at Sheba Tannery, Tigray, Northern Ethiopia. Trop Anim Health Prod 42: 1719-1722.

16. Berhanu W, Negussie H, Alemu S, Mazengia H (2011) Assessment on Major Factors That Cause Skin Rejection at Modjo Export Tannery, Ethiopia. Trop Anim Health Prod 43: 989-993.

17. Tadesse A, Fentaw E, Mekbib B, Abebe R, Mekuria S (2011) Study on the prevalence of ectoparasite infestation of ruminanats in and around Kombolcha and damage to fresh goat pelts and wet blue (pickled) skin at Kombolch Tannary, Northeastern Ethiopia. Ethiopian Veterinary Journal 15.

18. Ghosh S, Azhahianambi P, de la Fuente J (2006) Control of Ticks of Ruminants, With Special Emphasis on Livestock Farming Systems in India: Present and Future Possibilities for Integrated Control--A Review. Exp Appl Acarol 40: 49-66.

19. Engelbrecht A, Hoffman LC, Cloete SWP, Van Schalkwyk SJ (2009) Ostrich leather quality: a review. Anim Prod Sci 49: 549-557.

20. Abebe R, Tatek M, Megersa B, Sheferaw D (2011) Prevalence of Small Ruminant Ectoparasites and Associated Risk Factors in Selected Districts of Tigray Region, Ethiopia. Glob Vet 7: 433-437.

21. Abunna F, Tura J, Regassa A (2013) Status of Tick Infestation in Small Ruminants of Bedelle District, Oromia Region, Ethiopia. Global Veterinaria 8: 459-462.

22. Isse F, Said A, Ali M (2017) Hard Tick Distribution of Camels in and around Galkaio District, Somalia. Glob J Med Res 17

23. Adrian M, Nonga Hezron E, Mdegela Robinson H (2012) Tick infestations in extensively grazed cattle and efficacy trial of highciscypermethrin pour-on preparation for control of ticks in Mvomero district in Tanzania. BMC Vet Res 8: 224.

24. Okello-Onen J, Tukahirwa E, Perry B, Rowlands G, Nagda S, et al. (2003) The Impact of Tick Control on the Productivity of Indigenous Cattle Under Ranch Conditions in Uganda. Trop Anim Health Prod 35: 237-247.

25. Muruthi WC (2015) Phenotypic and Molecular Characterization of Hard Ticks (Acari: Ixodidae) Sampled from Wild Herbivores from Lake Nakuru and Tsavo National Parks in Kenya. Kenyatta University.

26. Nejash AA (2016) Review of Economically Important Cattle Tick and Its Control in Ethiopia. Advances in life Science and Technology 42: 51-64.

27. Abebe R, Fantahun T, Abera M, Bekele J (2010) Survey of ticks (Acari: Ixodidae) infesting cattle in two districts of Somali Regional State, Ethiopia. Vet World 3: 539-543. 
28. Gashaw BA, Mersha CK (2013) Pathology of Tick Bite Lesions in Naturally Infested Skin and Hides of Ruminants: A Review. Acta Parasitologica Globalis 4: 59-63.

29. Tolossa YH (2014) Ectoparasitism: Threat to Ethiopian small ruminant population and tanning industry. J Vet Med Anim Health 6: 25-33.

30. George JE, Pound JM, Davey RB (2004) Chemical Control of Ticks on Cattle and the Resistance of These Parasites to Acaricides. Parasitology 129: 353-366.

31. Martinez-Velazquez M, Castillo-Herrera GA, Rosario-Cruz R, FloresFernandez JM, Lopez-Ramirez J, et al. (2011) Acaricidal effect and chemical composition of essential oils extracted from Cuminum cyminum, Pimenta dioica and Ocimum basilicum against the cattle tick Rhipicephalus (Boophilus) microplus (Acari: Ixodidae). Parasito Res 108: 481-487.

32. Rao Z Abbas, Muhammad Arfan Zaman, Douglas D Colwell, John Gilleard, Zafar Iqbal (2014) Acaricide resistance in cattle ticks and approaches to its management: The state of play. Vet Parasitol 203 6-20.

33. Sajid MS, Iqbal Z, Khan MN, Muhammad G (2009) In Vitro and In Vivo Efficacies of Ivermectin and Cypermethrin against the Cattle Tick Hyalomma Anatolicum Anatolicum (Acari: Ixodidae). Parasitol Res 105: 1133-1138.

34. Kalala W, Magadula J, Mdegela H (2014) Evaluating Acaricidal Activity of Commiphora swynertonii (Burrt) bark Exudate against common Ticks in Tanzania. Int J Herb Med 2: 19-25.

35. Kaaya GP (2003) Prospects for Innovative Tick Control Methods in Africa. Int J Trop Insect Sci 23: 59-67.

36. Kirkland BH, Westwood GS, Keyhani NO (2004) Pathogenicity of entomopathogenic fungi Beauveria bassiana and Metarhizium anisopliae to Ixodidae tick species Dermacentor variabilis, Rhipicephalus sanguineus, and Ixodes scapularis. J Med entomol 41: 705-711.

37. Maniania NK, Nchu F, Ekesi S (2007) 10 Fungal pathogens for biocontrol of ticks.

38. Pirali-Kheirabadi K, Haddadzadeh $\mathrm{H}$, Razzaghi-Abyaneh M, Bokaie S, Zare R, et al. (2007) Biological Control of Rhipicephalus (Boophilus) Annulatus by Different Strains of Metarhizium Anisopliae, Beauveria Bassiana and Lecanicillium Psalliotae Fungi. Parasitol Res 100: 12971302.

39. Angelo IC, Fernandes ÉK, Bahiense TC, Perinotto WM, Moraes APR, et al. (2010) Efficiency of Lecanicillium lecanii to control the tick Rhipicephalus microplus. Vet Parasitol 172: 317-322.

40. Sun M, Ren Q, Guan G, Liu Z, Ma M, et al. (2011) Virulence of Beauveria Bassiana, Metarhizium Anisopliae and Paecilomyces Lilacinus to the Engorged Female Hyalomma Anatolicum Anatolicum Tick (Acari: Ixodidae). Vet Parasitol 180: 389-393.
41. Habeeb SM, Ashry HM, Saad MM (2017) Ovicidal Effect of Chitinase and Protease Enzymes Produced by Soil Fungi on the Camel Tick Hyalomma dromedarii Eggs (Acari: Ixodidae). J Parasit Dis 41: 268273.

42. Zekeya N, Mtambo M, Ramasamy S, Chacha M, Ndakidemi PA, et al. (2019) First record of an entomopathogenic fungus of tomato leafminer, Tuta absoluta (Meyrick) in Tanzania. Biocontrol Sci Technol 29: 626-637.

43. Alves RRN, Mota ELS, Dias TLP (2018) Use and commercialization of animals as decoration. In: Nobrega Alves RR, Albuquerque UP (eds) Ethnozoology: Animals in our Lives. Academic Press 261-275.

44. Nsubuga D, Banadda N, Kiggundu N (2019) Innovations in ValueAddition of Agricultural By-Products in Uganda. J Environ Prot Sci 10: 1493-1506.

45. Lee S, Kim JY, Yi MH, Lee IY, Fyumagwa R, et al. (2019) Comparative microbiomes of ticks collected from a black rhino and its surrounding environment. Int J Parasitol Parasites Wildl 9: 239-243.

46. Oundo JW (2019) Pathogens and blood feeding patterns of questing ticks in Maasai Mara wildlife ecosystem, Kenya. Doctoral dissertation, University of Nairobi, Kenya.

47. Sun M, Ren Q, Guan G, Li Y, Han X, et al. (2013) Effectiveness of Beauveria Bassiana Sensu Lato Strains for Biological Control Against Rhipicephalus (Boophilus) Microplus (Acari: Ixodidae) in China. Parasitol Res 62: 412-415.

48. Fernandes ÉK, Bittencourt VR, Roberts DW (2012) Perspectives on the potential of entomopathogenic fungi in biological control of ticks. Exp Parasitol 130: 300-305

49. Elham AS, Shigidi MT, Hussan SM (2013) Activity of Scopulariopsis brevicaulis on Hyalomma anatolicum and Amblyomma lepidum (Acari: Ixodidae). J Med Sci 13: 667-675.

50. Gindin G, Samish M, Zangi G, Mishoutchenko A, Glazer I (2003) The susceptibility of different species and stages of ticks to entomopathogenic fungi. Ticks and Tick-Borne Pathogens 283-288.

51. Wasinpiyamongkol L, Kanchanaphum P (2019) Isolating and identifying fungi to determine whether their biological properties have the potential to control the population density of mosquitoes. Heliyon 5: e02331.

52. Tavassoli M, Ownag AG, Meamari R, Rahmani S, Mardani K, et al. (2009) Laboratory evaluation of three strains of the entomopathogenic fungus Metarhizium anisopliae for controlling Hyalomma anatolicum and Haemaphysalis punctata. Iran J Vet Res 3: 11-15.

53. Sun M, Ren Q, Liu Z, Guan G, Gou H, et al. (2011) Beauveria bassiana: Synergistic effect with acaricides against the tick Hyalomma anatolicum anatolicum (Acari: Ixodidae). Exp Parasitol 128: 192-195. 